\title{
Influence of Cardiovascular Risk Factors on Aortic Wall Motion After Repair of Type A Aortic Dissection
}

\section{An Electrocardiography-Gated Computed Tomography Study}

\author{
Mariagrazia Croccia, MD, $\mathrm{PhD}^{1}$, Maurizio Levantino, $\mathrm{MD}^{2}$, Paolo Marraccini, $\mathrm{MD}^{3}$, \\ Federico Franchi, $\mathrm{MD}^{4}$, Uberto Bortolotti, $\mathrm{MD}^{2 *}$ \\ ${ }^{1}$ Department of Cardiac Surgery, Heart Transplantation Division, University of Siena, Siena, Italy; ${ }^{2}$ Section of Cardiac Surgery and \\ ${ }^{3}$ Division of Radiology, University Hospital, Pisa, Italy; ${ }^{4}$ Department of Anesthesia and Intensive Care, University of Siena, Siena, Italy
}

\begin{abstract}
Background: We aimed to evaluate size changes of the thoracic aorta during the cardiac cycle with dynamic computed tomographic angiography (CTA) at specific anatomic landmarks in patients who previously underwent ascending aorta repair because of type A dissection, and to correlate aortic wall motion with several cardiovascular risk factors. Methods: From December 2008 to December 2010, 18 patients (14 men and 4 women, mean age $64 \pm 12$ years) with previous aortic repair underwent electrocardiography-gated CTA follow-up. Aortic systolic and diastolic diameter and cross-sectional area were measured at 4 levels: $1 \mathrm{~cm}$ proximal (level A) and 1 (B), 3 (C), and $10 \mathrm{~cm}$ (D) distal to the origin of the left subclavian artery. Results were assessed according to age and presence of diabetes, hypertension, and smoking. Results: This morpho-functional evaluation of aortic wall motion demonstrated a significant influence $(P<0.05)$ of hypertension at level $A$ and $D$ and diabetes at level $D$. Smoking had a borderline significance at level C and D. No significant correlation with age was evident, with results not significantly different in patients $\leq \mathbf{5 5}$ and $>55$ years. Conclusions: Smoking, diabetes, and hypertension play a role in impairing aortic size variations. These variations might predict wall structural alterations due to cardiovascular risk factors before they
\end{abstract}

become morphologically evident. This might influence timing of surveillance following repair of acute dissection, allowing it to be specifically tailored for any single subject.

Copyright @ 2013 Science International Corp.

\section{Key Words}

Aortic dissection - Repair of aortic dissection Computed tomography

\section{Introduction}

Among aortic diseases, dissection is relatively common, with an incidence of 2.9 cases/100,000 persons per year, its natural history being characterized by high early and late mortality rates [1]. As confirmed by recent guidelines [2], urgent surgical repair is the gold standard for treatment of dissection involving the ascending aorta (AA) (Stanford type A), and the suggested imaging techniques for preoperative and postoperative evaluation in this setting are computed tomographic angiography (CTA) or magnetic resonance (MR) angiography [2]. Standard imaging techniques, like computed tomography, give a complete diagnostic work-up, but cannot measure dynamic, pulseassociated changes of the aortic geometry, resulting in sizing failures.

*Corresponding author:

Uberto Bortolotti, MD

Sezione Autonoma di Cardiochirurgia Universitaria

Via Paradisa, 2

56124 Pisa, Italy

Tel.: +3950 995250, Fax: +39 50 541647, E-Mail: uberto.bortolotti@med.unipi.it 
During the cardiac cycle, the thoracic aorta has the important role to reduce pulse pressure, smooth peripheral blood flow, and enhance the efficacy of the entire cardiovascular system; its abnormalities may result in several cardiovascular diseases [3]. Furthermore, aortic elasticity is extensively accepted as an independent predictor of adverse cardiovascular outcomes at an early stage [4]. Hence, the evaluation of aortic elasticity noninvasively appears of great interest. With the development and application of dynamic imaging techniques such as electrocardiography (ECG)-triggered CTA and MR angiography, it has become possible to study the aortic motion and distention during the cardiac cycle $[5,6]$.

The aim of this study was to utilize ECG-gated CTA to examine thoracic aortic motion during the cardiac cycle at specific anatomic landmarks in patients who previously have undergone AA surgery for type $A$ dissection. First, diameter and cross-sectional area changes were analyzed at different levels; second, a correlation between several cardiovascular risk factors such as smoking, diabetes, hypertension, and age and aortic wall motion was done to gain a new insight into elastic properties of the thoracic aorta in order to possibly give such patients a tailored follow-up.

\section{Materials and Methods}

A series of patients who had previously undergone $A A$ repair for acute Stanford type A dissection were studied using dynamic CTA. This study was approved by each institutional review board, and written informed consent was obtained from each patient before performing the investigation.

\section{Patient Data}

From December 2008 to December 2010, 44 patients underwent surgery because of Stanford type A aortic dissection. Among them, 18 patients, selected because of no extension of dissection to the arch or descending aorta, were examined with ECG-gated CTA and included in the study. The clinical characteristics are summarized in Table 1. There were 14 men $(78 \%)$ and 4 women $(22 \%)$, with a mean age of $64 \pm 12$ years; dividing them into two age groups ( $\leq 55$ and $>55$ years), 12 $(67 \%)$ were $>55$ years. All were in sinus rhythm; 7 patients (39\%) had diabetes controlled with oral therapy, 10 (56\%) had hypertension (defined as a systolic pressure $>140 \mathrm{~mm} \mathrm{Hg}$ and a diastolic pressure $>90 \mathrm{~mm} \mathrm{Hg}$ ) treated with beta-blockers, 6 (33\%) were smokers, and 2 (11\%) had dyslipidemia. Two patients $(11 \%)$ had undergone aortic valve replacement for valve regurgitation prior to acute aortic dissection. No patient had chronic pulmonary disease or extracardiac arteriopathy.
Table 1. Summary of Preoperative Characteristics and Operative Details

Number of

patients $=18$

$\%$

Clinical characteristics

Male/female

$14 / 4$

Diabetes

Hypertension

Smoking

Mean age (years)

Age range (years)

Age $\leq 55 \mathrm{yr}$

Age $>55 \mathrm{yr}$

Sinus rhythm

Dyslipidemia

Previous heart surgery

COPD

Extracardiac arteriopathy

Type of operation

Composite graft

$A A$ replacement $+C A B G$

$A A+$ hemiarch replacement

$\mathrm{AA}$ replacement

7

10

6

$64 \pm 12$

47-83

6

12

18

2

2

$\%$

COPD, chronic obstructive pulmonary disease; $A A$, Ascending aorta; $C A B G$, coronary artery bypass grafting.

\section{Operative Data}

At first presentation, all patients were affected by Stanford type A acute aortic dissection and underwent emergency operation. The procedures performed are listed in Table 1: 11 (61\%) had replacement of the aortic valve and AA with coronary artery reimplantation, $3(17 \%)$ had $A A$ repair and coronary artery bypass grafting, 2 (11\%) had AA and hemiarch repair, and $2(11 \%)$ had simple AA repair.

\section{Follow-up}

Patients undergoing repair of an acute aortic dissection are usually assessed clinically and by CTA or MR angiography at discharge and then 1, 3, 6, and 12 months after surgery and, if stable, annually thereafter [2]. In the present series, follow-up ranged from January 2010 to December 2011, while ECG-gated CTA was performed at a mean interval of $12.2 \pm 1.7$ months from operation.

\section{Image Acquisition}

Our CTA (Light-Speed VCT 64, GE Healthcare, Milwaukee, WI, USA) protocol has been described previously [7].

Using retrospective ECG-gating, reconstruction of at least 10 series synchronized with the cardiac cycle $(0-90 \%$ of $R-R$ time with steps of $10 \%$ ) was obtained. Transaxial images were reconstructed using a slice thickness of $0.625 \mathrm{~mm}$ and 0.625 increments. The data were then transferred to a dedicated workstation (Advantage Workstation 4.3, GE Healthcare, Mil- 


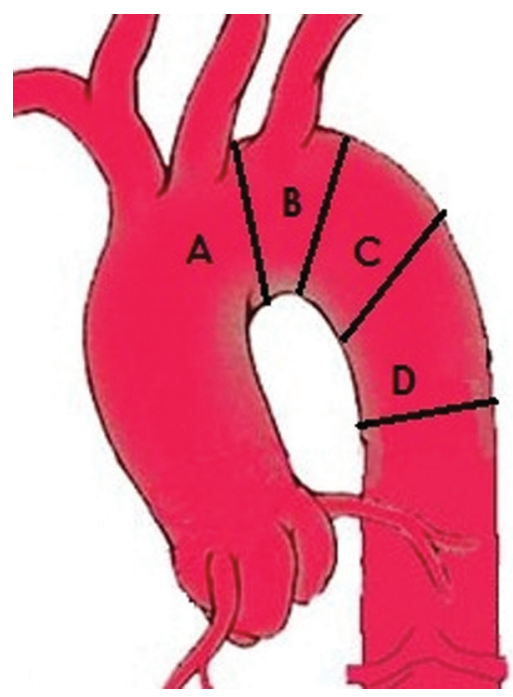

Figure 1. Anatomical levels: $1 \mathrm{~cm}$ proximal (level A), $1 \mathrm{~cm}$ (level B), $3 \mathrm{~cm}$ (level C), and $10 \mathrm{~cm}$ distal to left subclavian artery (level D).

waukee, WI, USA) for postprocessing. We used multiplanar reconstruction of the thoracic aorta in each ECG-gated series and a specific program for the automatic recognition of the contrasted vessel lumen for evaluating diameter, circumference, and area of the thoracic aorta in the different phases of the cardiac cycle, using manual correction when necessary. According to the protocol used [7], data acquisition was obtained at a heart rate $\leq 65$ beats per minute for best temporal resolution; to obtain this, beta-blockers were administered when required.

Four anatomical levels were selected to evaluate aortic size changes: $1 \mathrm{~cm}$ proximal to the origin of the left subclavian artery (level A), and $1 \mathrm{~cm}$ (level B), $3 \mathrm{~cm}$ (level C), and $10 \mathrm{~cm}$ distal to the left subclavian artery (level D), as shown in Figure 1. The measurements were done by two observers who performed the segmentation twice for calculation of intraobserver and interobserver repeatability. After segmentation of the aortic lumen in each cardiac phase, diameter and area changes over the cardiac cycle were measured. Diameter and crosssectional area changes were considered as the difference between minimum and maximum size during the cardiac cycle, measured between the outer walls of the aorta (adventitia to adventitia) at any level, in a reconstructed plane perpendicular to the vessel centerline. Additionally, data were assessed for the presence of diabetes, hypertension, smoking, and age, dividing the study population into two groups, those $\leq 55$ years and those older.

\section{Data Analysis}

Statistical analysis was performed using the software SPSS 11.5 (SPSS Inc, Chicago, IL, USA) and GraphPad PRISM version 4.0 (GraphPad, San Diego, CA, USA). All data on diameter and cross-sectional area are presented as mean \pm standard deviation (SD) and categorical variables are expressed as number and percentage. To test normal distribution, the KolmogorovSmirnov test was used. To analyze statistical differences between minimum and maximum diameters and areas during $\mathrm{R}-\mathrm{R}$ interval at each level in each patient, paired sample $T$-test was applied. To evaluate the role of different cardiovascular risk factors on diameters and area variations, Student's $T$-test for unpaired data was used. A $p$-value $\leq 0.05$ was considered statistically significant. The intraobserver and interobserver repeatability was analyzed with Bland and Altman's [8,9] comparison method. All the measurements demonstrated good repeatability.

\section{Results}

\section{Mean Aortic Diameter}

The results are shown in Table 2 and in Figure 2. The mean aortic diameters demonstrated statistically significant change $(P \leq 0.05)$ during the cardiac cycle at each anatomical landmark. We found a mean change of $5.5 \%$ at level A (range 0-10.3; SD 3.3, with absolute change of $1.6 \pm 1.03 \mathrm{~mm}$ ), $5.2 \%$ at level $B$ (range 8-8.8; SD 2.8, with absolute difference of $1.4 \pm$ $0.7 \mathrm{~mm}$ ), 5.1\% at level C (range 1.7-8.6; SD 2.06, absolute change $1.6 \pm 0.7 \mathrm{~mm}$ ), and $5.8 \%$ at level $\mathrm{D}$ (range 0-18.1; SD 5.7, absolute difference $2 \pm 2.3 \mathrm{~mm}$ ). Comparison of the intraobserver diameter measurements revealed a mean bias of $0.19 \mathrm{~mm}$, while the interobserver diameter measurements showed a mean bias of $0.08 \mathrm{~mm}$.

\section{Mean Aortic Area}

The results are shown in Table 2 and in Figure 3. The mean aortic area changes were statistically significant $(P \leq 0.05)$ during the cardiac cycle at each anatomical landmark. Considering area changes during the cardiac cycle, the mean change was $8.3 \%$ at level A (range 0.6-16.9; SD 5.6, absolute value $56 \pm$ $44.7 \mathrm{~mm}^{2}$ ), 8.4\% at level B (range 1.1-15.4; SD 4.9, with absolute change of $\left.49.9 \pm 35.9 \mathrm{~mm}^{2}\right), 19.6 \% 3 \mathrm{~cm}$ at level C (range 3-65; SD 20.8, with absolute difference of $189.4 \pm 274 \mathrm{~mm}^{2}$ ), and $11.7 \%$ at level D (range 1.8-29.2; SD 9.7, absolute difference $97.2 \pm 105 \mathrm{~mm}^{2}$ ).

Comparison of the intraobserver area measurements revealed a mean bias of $4.07 \mathrm{~mm}^{2}$, while the interobserver area measurements demonstrated a mean bias of $1.91 \mathrm{~mm}^{2}$.

\section{Evaluation of Cardiovascular Risk Factors}

The results are shown in Tables 3 and 4. According to patient age, no statistical difference was observed, either in aortic diameter or in aortic area changes. The only significant data were the change in aortic percentage 


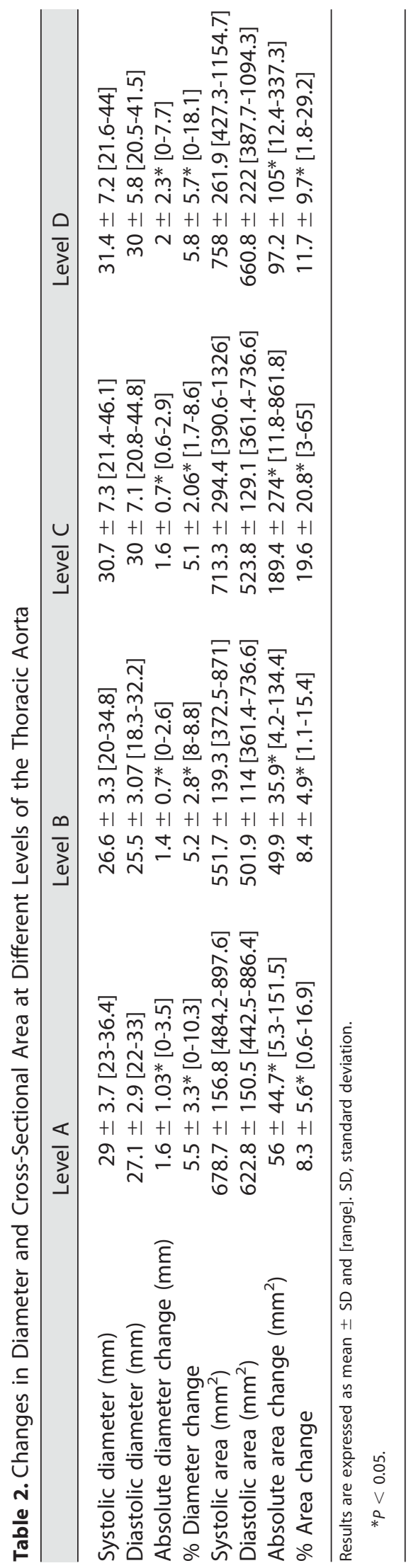

area at level $D$, being $19.4 \pm 11 \%$ the change rate in patients $\leq 55$ years and $7.9 \pm 6.8 \%$ in those $>55$ years.

Considering diabetes, there were significant differences at level $D$, both for diameter and area change. In diabetic patients, at level $D$, the absolute diameter change was $3.7 \pm 3 \mathrm{~mm}$ and the percentage change was $10.4 \pm 6.8 \%$. In nondiabetic patients these values were $0.9 \pm 0.7 \mathrm{~mm}$ and $2.9 \pm 2 \%$, respectively, reaching a $p$-value of 0.05 for absolute diameter change and 0.03 for percentage change. The percentage area change differences reached a $p$-value of 0.04 , being $21.5 \pm 12.8 \%$ of the percentage area change in diabetics and $8.5 \pm 6.4 \%$ in nondiabetics.

As for hypertension, at level $A$, hypertensive patients had a mean aortic diameter modification of $1.1 \pm 0.9 \mathrm{~mm}$ and a percentage change of $3.8 \pm 3.3 \%$, while in nonhypertensive patients the same measurements revealed $2.2 \pm 0.8 \mathrm{~mm}$ of mean diameter and $7.8 \pm 2 \%$ of percentage change $(P=0.01)$. At level $D$, mean diameter change was $0.7 \pm 0.4 \mathrm{~mm}$ in hypertensives and $3.6 \pm 2.8 \mathrm{~mm}$ in nonhypertensives $(P=$ 0.02 ). At this level, percentage diameter change was $2.8 \pm 1.9 \%$ in hypertensives and $9.5 \pm 6.7 \%$ in nonhypertensives $(P=0.03)$.

In tobacco smokers, a borderline significance was evident at level $C$ and $D$ for aortic area change. At level $C$ there was a mean aortic area change of $29.6 \pm 12.5$ $\mathrm{mm}^{2}$ in smokers and $303.7 \pm 317.9 \mathrm{~mm}^{2}$ in nonsmokers $(P=0.06)$ with a percentage area change, respectively, of $6.2 \pm 2.7 \%$ and $29.2 \pm 23 \%(P=0.04)$. At level $D$, mean area modification was $30.1 \pm 14.5 \mathrm{~mm}^{2}$ in the smokers group and $145.1 \pm 116.9 \mathrm{~mm}^{2}$ in the other $(P=0.04)$ group, while percentage area change was $6.2 \pm 3.9 \%$ in smokers and $15.7 \pm 10.9 \%$ in nonsmokers $(P=0.06)$.

\section{Discussion}

The present feasibility study was intended to evaluate aortic size changes in order to characterize type A dissection in a time-resolved method, obtaining morphological and functional information at the same time, which could be useful to achieve possible indicators of the course of the disease. Our results, even though they were derived from a small patient sample, show that there is a correlation between aortic size modification and some cardiovascular risk factors and that their impact is different at different anatomical levels. These data, even if obtained from a different subset of patients (dissected aorta), confirm other 


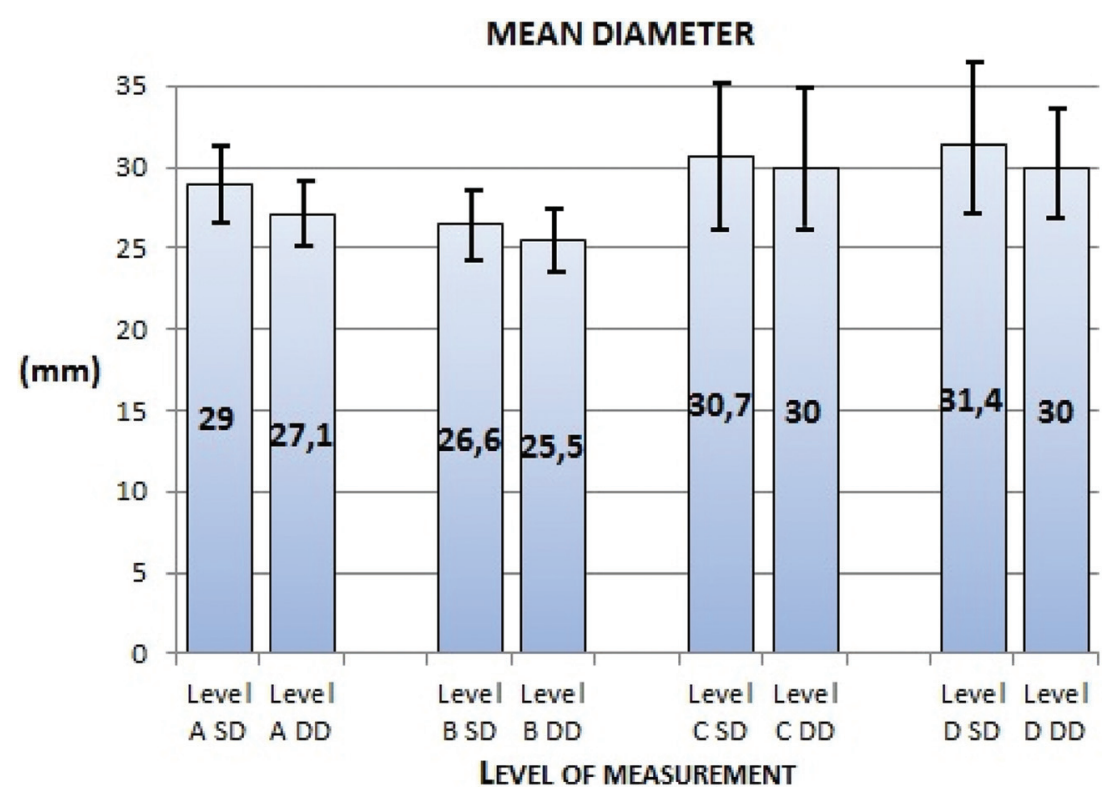

Figure 2. A histogram showing mean diameter during cardiac cycle at different anatomical levels. SD, systolic diameter; DD, diastolic diameter.

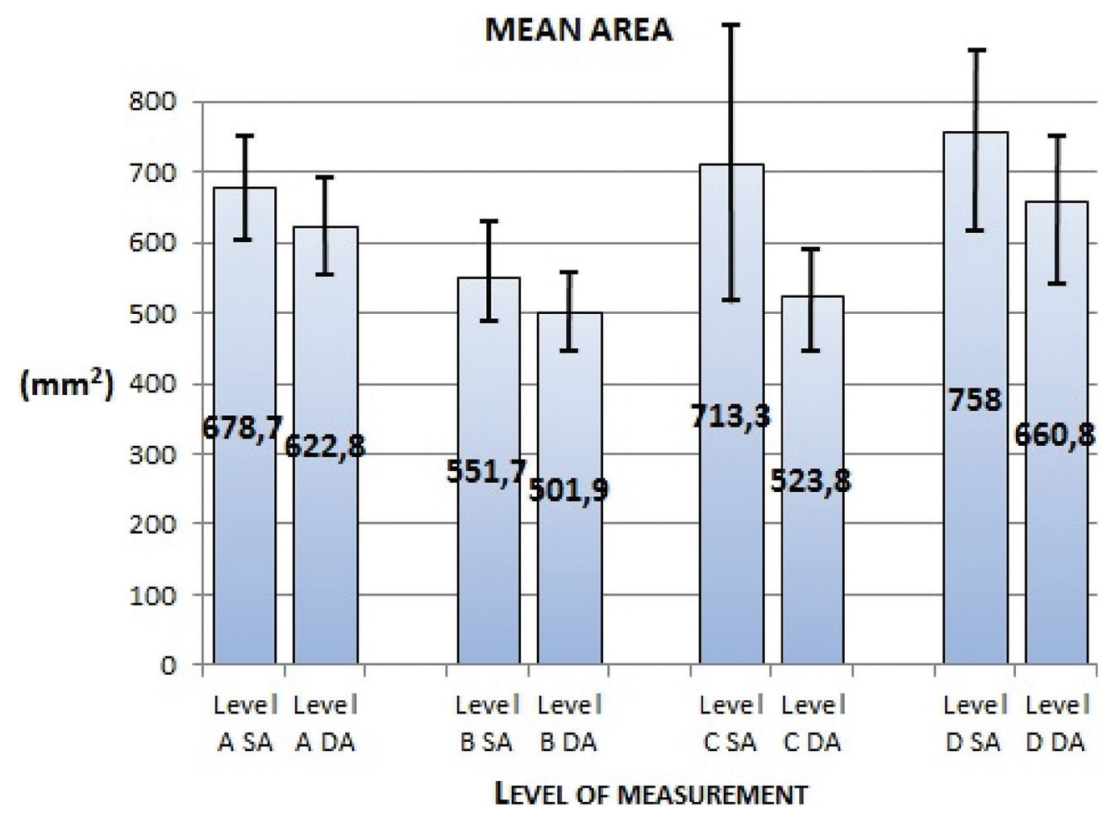

Figure 3. A histogram showing mean area during cardiac cycle at different anatomical levels. SA, systolic area; DA, diastolic area.

observations from the literature [10-13], providing further information on the dynamic behavior of the aorta and focusing on specific risk factors not analyzed before, such as diabetes and smoking.

With the development and application of dynamic imaging techniques such as ECG-triggered CTA and MR angiography, it has become possible to study the aortic motion and distention during the cardiac cycle
$[5,6]$. Several studies showed significant aortic distention at important landmarks in the abdominal, ascending, and descending thoracic aorta $[5,6,14,15]$.

van Herwaarden et al. [5] studied aortic distention using ECG-triggered MR angiography, showing that in patients with atherosclerotic aneurysm disease, the aortic dimensions at the level of and proximal to the aneurysm neck change during the cardiac cycle. Muhs 
Table 3. Relation Between Aortic Diameter and Area Changes With Age and Presence of Diabetes

\begin{tabular}{|c|c|c|c|c|c|c|c|}
\hline Mean $\pm S D$ & & Age $\leq 55 \mathrm{yr}$ & AGE $>55 \mathrm{yr}$ & $p$ & DIAB & $n-D I A B$ & $P$ \\
\hline DIAM. CH. (mm) & $A$ & $1.7 \pm 0.3$ & $1.6 \pm 1.3$ & n.s. & $1.8 \pm 0.5$ & $1.5 \pm 1.3$ & n.s. \\
\hline \% DIAM. $\mathrm{CH}$. & & $5 \pm 3.9$ & $6.3 \pm 1.1$ & n.s. & $6.7 \pm 1.6$ & $4.7 \pm 3.9$ & n.s. \\
\hline AREA CH. $\left(\mathrm{mm}^{2}\right)$ & & $65.2 \pm 27$ & $51.9 \pm 52.6$ & n.s. & $48.1 \pm 23.6$ & $58.5 \pm 50.8$ & n.s. \\
\hline$\%$ AREA CH. & & $11.5 \pm 4.4$ & $6.7 \pm 5.7$ & n.s. & $9.1 \pm 4.6$ & $8 \pm 6.2$ & n.s. \\
\hline DIAM. CH. (mm) & B & $1.2 \pm 0.9$ & $1.8 \pm 0.7$ & n.s. & $1.5 \pm 0.6$ & $1.3 \pm 0.8$ & n.s. \\
\hline$\%$ DIAM. $\mathrm{CH}$. & & $4.6 \pm 3.3$ & $5.4 \pm 2.6$ & n.s. & $5.6 \pm 2.2$ & $4.9 \pm 3.2$ & n.s. \\
\hline AREA CH. $\left(\mathrm{mm}^{2}\right)$ & & $53.2 \pm 27.5$ & $48.2 \pm 41.1$ & n.s. & $36.4 \pm 12.4$ & $54.4 \pm 40.5$ & n.s. \\
\hline$\%$ AREA CH. & & $10.3 \pm 5$ & $7.5 \pm 4.8$ & n.s. & $6.7 \pm 1.4$ & $9 \pm 5.5$ & n.s. \\
\hline DIAM. CH. (mm) & $\mathrm{C}$ & $1.4 \pm 0.4$ & $1.7 \pm 0.8$ & n.s. & $1.6 \pm 0.5$ & $1.6 \pm 0.8$ & n.s. \\
\hline \% DIAM. CH. & & $4.4 \pm 2.3$ & $5.5 \pm 2$ & n.s. & $4.6 \pm 2.1$ & $5.4 \pm 2$ & n.s. \\
\hline AREA CH. $\left(\mathrm{mm}^{2}\right)$ & & $395.6 \pm 419.1$ & $86.4 \pm 79.1$ & n.s. & $507.9 \pm 433.8$ & $83.3 \pm 74.1$ & n.s. \\
\hline$\%$ AREA CH. & & $34.9 \pm 30.7$ & $12 \pm 8.6$ & n.s. & $42.1 \pm 33.7$ & $12.1 \pm 7.7$ & n.s. \\
\hline DIAM. CH. (mm) & $\mathrm{D}$ & $3.8 \pm 3.4$ & $1.1 \pm 0.6$ & n.s. & $3.7 \pm 3$ & $0.9 \pm 0.7$ & 0.05 \\
\hline \% DIAM. CH. & & $10.3 \pm 8.1$ & $3.6 \pm 2$ & n.s. & $10.4 \pm 6.8$ & $2.9 \pm 2$ & 0.03 \\
\hline AREA CH. $\left(\mathrm{mm}^{2}\right)$ & & $170 \pm 150.4$ & $60.8 \pm 55.7$ & n.s. & $209.7 \pm 156.7$ & $59.7 \pm 52$ & n.s. \\
\hline$\%$ AREA CH. & & $19.4 \pm 11$ & $7.9 \pm 6.8$ & 0.05 & $21.5 \pm 12.8$ & $8.5 \pm 6.4$ & 0.04 \\
\hline
\end{tabular}

SD, standard deviation; DIAM, diameter; $C H$, change; DIAB, diabetic; n-DIAB, non-diabetic; A, B, C, D, aortic levels (see text). n.s. = not significant; $p \leq 0.05$ was considered significant.

Table 4. Relation Between Aortic Diameter and Area Changes With Hypertension and Smoking History

\begin{tabular}{|c|c|c|c|c|c|c|c|}
\hline Mean $\pm S D$ & & HT & $\mathrm{n}-\mathrm{HT}$ & $p$ & Smoking & No smoking & $p$ \\
\hline DIAM. CH. (mm) & $A$ & $1.1 \pm 0.9$ & $2.2 \pm 0.8$ & 0.01 & $1.1 \pm 0.7$ & $1.8 \pm 1.1$ & n.s. \\
\hline$\%$ DIAM. $\mathrm{CH}$. & & $3.8 \pm 3.3$ & $7.8 \pm 2$ & 0.01 & $4.1 \pm 2.8$ & $6.1 \pm 3.4$ & n.s. \\
\hline AREA CH. $\left(\mathrm{mm}^{2}\right)$ & & $36.1 \pm 33.8$ & $75.8 \pm 48.1$ & n.s. & $44.9 \pm 34.4$ & $63.9 \pm 52$ & n.s. \\
\hline$\%$ AREA $\mathrm{CH}$. & & $5.8 \pm 5.9$ & $10.7 \pm 4.5$ & n.s. & $7.5 \pm 6.1$ & $9 \pm 5.7$ & n.s. \\
\hline DIAM. CH. (mm) & $\mathrm{B}$ & $1.4 \pm 0.7$ & $1.3 \pm 0.8$ & n.s. & $1.4 \pm 0.9$ & $1.4 \pm 0.7$ & n.s. \\
\hline$\%$ DIAM. $\mathrm{CH}$. & & $5.5 \pm 3$ & $4.7 \pm 2.6$ & n.s. & $5.5 \pm 3.8$ & $5 \pm 2.3$ & n.s. \\
\hline AREA CH. $\left(\mathrm{mm}^{2}\right)$ & & $48.2 \pm 33$ & $55.5 \pm 41.7$ & n.s. & $43.8 \pm 34.9$ & $54.2 \pm 38.7$ & n.s. \\
\hline$\%$ AREA CH. & & $9.2 \pm 5.9$ & $7.6 \pm 4$ & n.s. & $8.3 \pm 6.3$ & $8.5 \pm 4.1$ & n.s. \\
\hline DIAM. CH. (mm) & C & $1.4 \pm 0.6$ & $1.8 \pm 0.8$ & n.s. & $1.2 \pm 0.5$ & $1.7 \pm 0.7$ & n.s. \\
\hline \% DIAM. CH. & & $5.2 \pm 1.9$ & $5 \pm 2.4$ & n.s. & $4.8 \pm 1.9$ & $5.2 \pm 2.2$ & n.s. \\
\hline AREA CH. $\left(\mathrm{mm}^{2}\right)$ & & $53.9 \pm 39.4$ & $325.1 \pm 345.7$ & n.s. & $29.6 \pm 12.5$ & $303.7 \pm 317.9$ & 0.06 \\
\hline$\%$ AREA $\mathrm{CH}$. & & $10.3 \pm 6.1$ & $29 \pm 26.5$ & n.s. & $6.2 \pm 2.7$ & $29.2 \pm 23$ & 0.04 \\
\hline DIAM. CH. (mm) & $\mathrm{D}$ & $0.7 \pm 0.4$ & $3.6 \pm 2.8$ & 0.02 & $0.9 \pm 0.6$ & $2.6 \pm 2.7$ & n.s. \\
\hline \% DIAM. $\mathrm{CH}$. & & $2.8 \pm 1.9$ & $9.5 \pm 6.7$ & 0.03 & $3.5 \pm 2.4$ & $7 \pm 6.6$ & n.s. \\
\hline AREA CH. $\left(\mathrm{mm}^{2}\right)$ & & $64.3 \pm 61.7$ & $130.1 \pm 133.6$ & n.s. & $30.1 \pm 14.5$ & $145.1 \pm 116.9$ & 0.04 \\
\hline$\%$ AREA $\mathrm{CH}$. & & $9.9 \pm 7.4$ & $13.6 \pm 12$ & n.s. & $6.2 \pm 3.9$ & $15.7 \pm 10.9$ & 0.06 \\
\hline
\end{tabular}

SD, standard deviation; DIAM, diameter; $\mathrm{CH}$, change; $\mathrm{HT}$, hypertensive; $\mathrm{n}-\mathrm{HT}$, nonhypertensive; $\mathrm{A}, \mathrm{B}, \mathrm{C}, \mathrm{D}$, aortic levels (see text). n.s. $=$ not significant; $p \leq 0.05$ was considered significant.

et al. [6] used dynamic CTA to demonstrate changes in thoracic aortic diameter in a patient with abdominal aortic aneurysm. According to their findings, the native aorta exhibits significant pulsation with each heart cycle, and this could have major implications for endograft efficacy and durability. van Prehn et al. [14] evaluated pulsatility and motion along the AA using ECG-triggered CTA. They demonstrated that the dynamics of the AA and the arch vessels were impressive: diameter and area change and center of mass movement of the AA were determined in 15 patients at surgically relevant anatomical levels. They showed significant size change at all levels, with the biggest pulsatility $5 \mathrm{~mm}$ distal to the coronary arteries. Such results should be taken into consideration when designing new branched or fenestrated endografts for aortic arch repair, since they could influence ultimate clinical success. Furthermore, the same group reported in 2009 [15] the use of dynamic CTA in pre- and postoperative thoracic endovascular aneurysm repair (TEVAR) patients, finding significant distention of the aortic arch and descending aorta during the cardiac 
cycle, before and after TEVAR. In other reports, similar observations were made using $\mathrm{M}$-mode ultrasound and intravascular ultrasound $[16,17]$.

Focusing on cardiovascular risk factors, our data have shown that smoking has an influence on aortic stiffness at level $C$ and $D$, even if at the latter level the statistical significance is borderline. At levels A and B, smoking shows no impact. This indicates and seems to confirm, at least in part, that tobacco smoking causes endothelial dysfunction decreasing flow-mediated vasodilatation [18]. In our patient subset, diabetes has a role on aortic wall motion at level $D$, but no significance is reached at more proximal levels. Further data might reinforce this finding, suggesting a different ultrastructural action of glucose at different levels of thoracic aorta. Should this be the case, such data might justify a more aggressive antidiabetic therapy in patients who previously underwent aortic operations on the ascending aorta, in order to prevent subsequent ultrastructural damage of the aortic wall and disease progression beyond the site of the original repair.

Our measurements showed that hypertension had a major impact on levels $A$ and $D$, confirming that it is one of the most important risk factors for aortic stiffness $[10,19]$. It must be underlined that all of our patients were treated with beta-blockers, which could also influence aortic plasticity $[20,21]$. However, close CT follow-up and aggressive treatment appear indicated to prevent possible progression of the aortic lesions in hypertensive patients.

Our data did not reveal any significant correlation between aortic wall motion and age. These findings differ from those present in the literature $[11,19,22]$ and might be due to the small sample size. Ganten et al. [11] showed an age-dependent decrease of aortic wall elasticity using ECG-CTA. Metafratzi et al. [19], in a MR-study, showed that aortic distensibility decreased with age and was correlated with various diseases, such as hypertension and atherosclerosis. More recently, Li et al. [22] evaluated 56 healthy patients using dynamic CTA showing an agedependent decrease of elasticity of the thoracic aorta, considered as due to the natural aging of such vessels.

The most frequently employed modalities for studying the aorta are CTA or MR angiography with 3-dimensional reconstruction which, however, give only static images of the aorta undergoing natural dynamic changes during the cardiac cycle [23]. Several techniques have been suggested to measure elastic properties of the aorta. These include pulse-wave velocity measurement employing either MR-velocity analysis [24] or Doppler ultrasound (DUS) [25], which monitor change of vessel cross-sectional area between systole and diastole. Among different proposed techniques, DUS is a simple and convenient method, but it is operator dependent and suffers from the difficulty of imaging all the parts of the aorta in a single view. Furthermore, the visualization during DUS can be influenced by the adjacent structures, particularly by bowel gas. In contrast, MR can be more objective than DUS and more useful in evaluation of vessel wall motion during the cardiac cycle [23], but its availability is limited, the acquisition of several pulse sequences increases the scan time, and monitoring of unstable patients can be difficult. Finally, the spatial resolution of MRI is currently inferior to that of CTA [11,22]. Therefore, although it causes radiation exposure, CTA is still the preferred method to screen aortic pathologies. With ECG-triggered CTA, original patient data can be reconstructed retrospectively during diastole, systole, or anywhere in between, and functional assessment can be obtained without additional radiation exposure or further examinations.

In conclusion, our results demonstrate that smoking, diabetes, and hypertension reduce aortic wall motion in patients who have undergone repair for acute aortic dissection when measured with dynamic CTA at specific anatomical landmarks. Despite the fact that our results are preliminary and based on a small sample size, representing the main limitation of the study, we believe they allow additional insight to be gained in the knowledge of aortic wall dynamics. Evaluation of aortic distensibility and stiffness might be useful to predict wall structural alterations due to the influence of cardiovascular risk factors, such as atherosclerosis, smoking, or diabetes, before they become morphologically apparent. The correlation between aortic distensibility and the clinical features of each patient could suggest different timing of surveillance, tailored and designed for each subject after repair of aortic dissection, together with more aggressive treatment of specific cardiovascular risk factors.

Comment on this Article or Ask a Question 


\section{REFERENCES}

1. Mészáros I, Mórocz J, Szlávi J, Schmidt J, Tornóci L, Nagy L, et al. Epidemiology and clinicopathology of aortic dissection. Chest. 2000;117:1271-1278. 10.1378/chest.117.5. 1271

2. Hiratzka LF, Bakris GL, Beckman JA, Bersin RM, Carr VF, Casey DE Jr, et al. 2010 ACCF/ AHA/AATS/ACR/ASA/SCA/ SCAI/SIR/STS/ $S V M$ guidelines for the diagnosis and management of patients with thoracic aortic disease: a report of the American College of Cardiology Foundation / American Heart Association Task Force on Practice Guidelines, American Association for Thoracic Surgery, American College of Radiology, American Stroke. Association, Society of Cardiovascular Anesthesiologists, Society for Cardiovascular Angiography and Interventions, Society of Interventional Radiology, Society of Thoracic Surgeons, and Society for Vascular Medicine. Circulation. 2010;121;e266-e369. 10.1161/CIR.0b013e3181d4739e

3. McEniery CM, Wilkinson IB, Avolio AP. Age, hypertension and arterial function. Clin Exp PharmacolPhysiol.2007;34:665-671.10.1111/ j.1440-1681.2007.04657.x

4. Lalande A, Khau Van Kien P, Walker PM, Zhu $L$, Legrand L, Claustres M, et al. Compliance and pulse wave velocity assessed by MRI detect early aortic impairment in young patients with mutation of the smooth muscle myosin heavy chain. J Magn Reson Imaging. 2008;28:1180-1187. 10.1002/jmri.21565

5. van Herwaarden JA, Bartels LW, Muhs $B E$, Vincken $K L$, Lindeboom MY, Teutelink A, et al. Dynamic magnetic resonance angiography of the aneurysm neck: conformational changes during the cardiac cycle with possible consequences for endograft sizing and future design. J Vasc Surg. 2006;44:22-28. 10.1016/j.jvs.2006.03.028

6. Muhs BE, Vincken KL, van Prehn J, Stone MK, Bartels LW, Prokop M, et al. Dynamic cine-CT angiography for the evaluation of the thoracic aorta; insight in dynamic changes with implication for thoracic endograft treatment. Eur J Vasc Endovasc Surg. 2006;32: 532-536. 10.1016/j.ejvs.2006.05.009

7. Liga R, Marini C, Coceani M, Filidei E, Schlueter M, Bianchi M, et al. Structural abnormalities of the coronary arterial wall-in addition to luminal narrowing-affect myocardial blood flow reserve. J Nucl Med. 2011;52: 1704-1712. 10.2967/jnumed.111.091009

8. Altman DG, Bland JM. Measurement in medicine: the analysis of method comparison studies. Statisticians. 1983;32:307-317. 10. 2307/2987937
9. Bland JM, Altman DG. Statistical methods for assessing agreement between two methods of clinical measurement. Lancet 1986;1:307310.

10. Laurent S, Katsahian S, Fassot C, Tropeano Al, Gautier I, Laloux B, et al. Aortic stiffness is an independent predictor of fatal stroke in essential hypertension. Stroke. 2003;34:12031206. 10.1161/01.STR.0000065428.03209.64

11. Ganten M, Krautter U, Hosch W, Hansmann J, von Tengg-Kobligk H, Delorme S, et al. Age related changes of human aortic distensibility: evaluation with ECG-gated CT. Eur Radiol. 2007;17:701-708. 10.1007/s00330-0060309-z

12. Blacher J, Safar ME, Guerin AP, Pannier B, Marchais SJ, London GM. Aortic pulse wave velocity index and mortality in end-stage renal disease. Kidney Int. 2003;63:18521860. 10.1046/j.1523-1755.2003.00932.x

13. Herrington DM, Kesler K, Reiber Jh, Davis W, Brown WV, Helms R, et al. Arterial compliance adds to conventional risk factors for prediction of angiographic coronary artery disease. Am Heart J. 2003;146:662-667. 10. 1016/S0002-8703(03)00254-0

14. van Prehn J, Vincken $K L$, Muhs $B E$, Barwegen GK, Bartels LW, Prokop M, et al. Toward endografting of the ascending aorta: insight into dynamics using dynamic cine-CTA. J Endovasc Ther. 2007;14:551-560. 10.1583/ 1545-1550(2007)14[551:TEOTAA]2.0.CO;2

15. van Prehn J, Bartels LW, Mestres G, Vincken $\mathrm{KL}$, Prokop M, Verhagen $\mathrm{HJ}$, et al. Dynamic aortic changes in patients with thoracic aortic aneurysms evaluated with electrocardiography-triggered computed tomographic angiography before and after thoracic endovascular aneurysm repair: preliminary results. Ann Vasc Surg. 2009;23:291-297. 10. 1016/j.avsg.2008.08.007

16. Arko FR, Murphy EH, Davis CM 3rd, Johnson ED, Smith ST, Zarins CK. Dynamic geometry and wall thickness of the aortic neck of abdominal aortic aneurysms with intravascular ultrasonography. J Vasc Surg. 2007;46:891897. 10.1016/j.jvs.2007.06.030

17. Goergen CJ, Johnson BL, Greve JM, Taylor CA, Zarins CK. Increased anterior abdominal aortic wall motion: possible role in aneurysm pathogenesis and design of endovascular devices. J Endovasc Ther. 2007;14:574-584. 10.1583/1545-1550(2007)14[574:IAAAWM]2. $0 . \mathrm{CO} ; 2$

18. Celermajer DS, Sorensen KE, Georgakopoulos D, Bull C, Thomas O, Robinson J, et al. Cigarette smoking is associated with doserelated and potentially reversible impair- ment of endothelium-dependent dilation in healthy young adults. Circulation. 1993;88: 2149-2155. 10.1161/01.CIR.88.5.2149

19. Metafratzi ZM, Efremidis SC, Scopelitou AS, De Roos A. The clinical significance of aortic compliance and its assessment with magnetic resonance imaging. J Cardiovasc Magn Reson. 2002;4:481-491. 10.1081/JCMR120016386

20. Shores J, Berger KR, Murphy EA, Pyeritz RE. Progression of aortic dilatation and the benefit of long-term beta-adrenergic blockade in Marfan's syndrome. N Engl J Med. 1994;330:13351341. 10.1056/NEJM199405123301902

21. Suzuki T, Isselbacher EM, Nienaber CA, Pyeritz RE, Eagle KA, Tsai $\Pi$, et al. Typeselective benefits of medications in treatment of acute aortic dissection (from the International Registry of Acute Aortic Dissection [IRAD]). Am J Cardiol. 2012;109:122127. 10.1016/j.amjcard.2011.08.012

22. Li N, Beck T, Chen J, Biermann C, Guo L, Sun $\mathrm{H}$, et al. Assessment of thoracic aortic elasticity: a preliminary study using electrocardiographically gated dual-source CT. Eur Radiol. 2011;21:1564-1572. 10.1007/s00330011-2077-7

23. Duvernoy O, Coulden R, Ytterberg C. Aortic motion: a potential pitfall in $\mathrm{CT}$ imaging of dissection in the ascending aorta. J Comput Assist Tomogr. 1995;19:569-572. 10.1097/ 00004728-199507000-00012

24. Markl M, Wallis W, Strecker C, Gladstone BP, Vach W, Harloff A. Analysis of pulse wave velocity in the thoracic aorta by flowsensitive four-dimensional MRI: reproducibility and correlation with characteristics in patients with aortic atherosclerosis. J Magn Reson Imaging. 2012;35:1162-1168. 10.1002/ jmri.22856

25. Nollen GJ, Westerhof BE, Groenink M, Osnabrugge A, van der Wall EE, Mulder BJ. Aortic pressure-area relation in Marfan patients with and without beta blocking agents: a new non-invasive approach. Heart. 2004;90: 314-318. 10.1136/hrt.2003.010702

Cite this article as: Croccia $M$, Levantino $M$, Marraccini P, Franchi F, Bortolotti U. Influence of Cardiovascular Risk Factors on Aortic Wall Motion After Repair of Type A Aortic Dissection: An Electrocardiography-Gated Computed Tomography Study.Aorta2013;1(5):235-243. DOl:http:// dx.doi.org/10.12945/j.aorta.2013.13-034 


\section{EDITOR'S COMMENTS AND QUESTIONS}

\section{Editor's Comments:}

The authors are to be congratulated on a preliminary foray into engineering assessment of the dissected aorta with $\mathrm{CT}$ imaging.

\section{Editor's Questions:}

1. You do not measure distensibility. You are measuring only dimensional change. BP in systole and diastole is needed to measure distensibility. It could be that the differences in dimensional change are all consequent to pressure differences between groups. Please comment.

It is correct that differences in dimensions could be due to variations of blood pressure. Indeed, such findings have been observed also in healthy subjects. We have confirmed what was observed also by others (included in our Reference list), but we think all these data are not only useful to study aortic elasticity but also to determine their morphofunctional significance. For example, it is important to understand whether specific risk factors may influence aortic wall rigidity or influence stent sizing in patients undergoing endovascular treatment.

2. What did you expect to find in this study? How did you anticipate that the groups would differ in their properties?

What we expected to find was the potential influence of risk factors (such as diabetes, smoking, etc.) on aortic wall rigidity.

3. Why did you choose patients post dissection repair? Why not look at non-dissected aneurysms?

This particular group of patients was selected because most studies in the literature do not consider patients with aortic dissection.
4. What do you make of the direction of the size changes (diabetics expanded more, smokers and hypertensives less)?

Different risk factors had an influence on aortic sizes at different levels. These preliminary findings may be partly unclear and should be verified with further studies on a larger patient sample. In general, they should indicate the need for a more aggressive medical therapy and change of life style.

5. Why did you perform so many composite grafts for acute dissection?

The high percentage of composite grafts may be explained by the fact that some of the patients had a diseased aortic valve; in others with significant aortic insufficiency, the surgeons most likely did not have enough experience at that time with aortic valve repair or with aortic remodeling or resuspension techniques.

6. Why did some patients have CABG? How did you know $C A B G$ was indicated?

Three patients had CABG because of dissection causing detachment of the right coronary ostium.

7. Did you check for gender differences in size change? If so, please provide results.

We did not check for gender differences because of the small number of patients and significant sex differences (males $=14$, females $=4$ ).

8. What is the spatial resolution of the CT scan? You are looking to measure size changes of about $1 \mathrm{~mm}$. Is this really feasible and reliable? The spatial resolution of the CAT scan used is $<0.5$ $\mathrm{mm}$; thus, a variation of $1 \mathrm{~mm}$ may be detected.

9. It is highly speculative at this point to say that we can predict aortic behavior based on size change data. Please comment.

We agree that such a conclusion is highly speculative. For this reason we have stressed the fact that our results must be verified on a larger patient sample. 